\title{
Violent victimisation of psychiatric patients: a Swedish case-control study
}

\author{
Joakim Sturup · Karolina Sorman • \\ Per Lindqvist • Marianne Kristiansson
}

Received: 22 July 2009/ Accepted: 27 October 2009/Published online: 16 November 2009

(c) The Author(s) 2009. This article is published with open access at Springerlink.com

\begin{abstract}
Objectives To report the rate of violent victimisation of psychiatric patients 1 year before interview and to examine the relative rate in comparison to the general population.

Method Cases were recruited from two public psychiatric hospitals in Stockholm County $(n=390)$. The controls comprised gender- and age-matched people interviewed in an annual national survey of living conditions $(n=1,170)$.

Results Twenty percent of the patients had been victimised during the preceding year. The relative rate was six times higher than that of the controls. Women appeared to be most vulnerable with a tenfold risk increase.

Conclusions The findings stress that psychiatric patients are vulnerable to other people's violent behaviour.
\end{abstract}

Keywords Victimisation - Violent victimisation ·

Violence $\cdot$ Mental disorder

\section{Introduction}

Violence towards people with mental disorders appears to be a neglected area in research as well as in clinical practice. This stands in contrast to the well investigated

J. Sturup $(\bowtie) \cdot$ K. Sorman · P. Lindqvist · M. Kristiansson Division of Forensic Psychiatry,

Department of Clinical Neuroscience,

Karolinska Institutet, Box 4044,

14104 Huddinge, Sweden

e-mail: joakim.sturup@ki.se link between mental disorders and violence perpetration. The concept of violent victimisation, as used here, refers to being subjected to physical violence in adult years [20]. The literature reports a high rate of such violence towards people with mental disorders [1, 2, 5, 17, 18, 21, 22, 25] and, even more importantly, controlled studies show that the risk is substantially higher compared to the general population [4, 19, 20, 23]. In a comprehensive review of studies from North America on violent behaviour by and towards people with mental disorder, Choe and colleagues [3] argue that victimisation of the mentally disordered should be of greater public health concern than their violent behaviour towards others.

Violent and sexual victimisation towards people with major mental disorder have been linked to poor community functioning, homelessness, hallucinations, delusions and low quality of life $[11,14,15]$. Up to date only three studies have examined the impact of treatment for the occurrence of victimisation [5, 9, 22]. Two UK studies found no significant reduction of victimisation in an intensive treatment group compared to a standard treatment group [5, 22]. A study from USA on people with severe mental illness showed that patients who were discharged to out-patient mandatory treatment were significantly less likely to be victimised than patients who were discharged without such compulsory treatment [9].

\section{Aims of the study}

Since there is no Swedish survey and no European controlled study of victimisation of psychiatric patients, this study was set up in order to report the rate of violent victimisation of general psychiatric patients and to examine the relative rate in comparison to the general population. 


\section{Materials and methods}

The setting

The study was conducted at the two largest public psychiatric hospitals in Stockholm County (1.9 million inhabitants) serving 289,000 and 400,000 people, respectively. Both hospitals provide voluntary as well as involuntary care. Patients were recruited from the two general psychiatric wards at the first hospital and from seven general psychiatric wards at the second hospital (excluding a ward negative to research). Patients were also recruited from the emergency unit at the second hospital, which serves the entire Stockholm County. This unit admits any individual for acute psychiatric evaluation and treatment. Prior psychiatric contact or referral by a third party is not required. The clinician may decide to admit the patient, to let the patient stay over night for observation, or to advise the person to return home.

Health care in Sweden, of any kind, is provided at a low cost to the individual who instead pays through general taxation. The private sector in psychiatry was, at the time of the study, small and of marginal importance. Treatment of patients with psychoactive substance dependence disorders in Stockholm County is run by a separate organisation, albeit co-morbidity is often seen in general psychiatry.
Cases

Psychiatric patients eligible for the study were between 18 and 60 years of age and returning home after an acute consultation or admission at any of the two hospitals and had a Swedish social security number (needed for access to records and national registers) and had a clinical ICD diagnosis [26] and had capacity to pursue an interview in Swedish or English. We chose to use the clinical diagnoses rather than conduct a specific diagnostic research interview, for two reasons; the exact diagnosis was not a main focus of the study and an extension of the research interview might have jeopardised the response rate and data quality.

Approximately 512 patients from the inpatient units of the two hospitals and 463 patients from the psychiatric emergency unit were eligible for the study. Thus, approximately 975 patients were eligible, 497 were approached (50\%) and 390 patients accepted to participate (78\% of all approached). Those who were not approached had left the hospital at a time when the research assistant was off duty (evenings, nights, weekends and holidays), and therefore no information about the non-approached patients could be retrieved. There were no significant difference between participants and refusals in terms of gender, age, diagnosis, admitted/not admitted, length of admission, voluntary/ involuntary care, and which hospital was concerned (Table 1).
Table 1 Victimisation among psychiatric patients in Stockholm: socio-demographic and clinical characteristics of cases, controls and refusals

\footnotetext{
* Not known

** Not applicable
}

\begin{tabular}{lclc}
\hline & $\begin{array}{l}\text { Cases } \\
(n=390)\end{array}$ & $\begin{array}{l}\text { Controls } \\
(n=1,170)\end{array}$ & $\begin{array}{l}\text { Refusals } \\
(n=107)\end{array}$ \\
\hline Gender & & & \\
Female & $203(52 \%)$ & $609(52 \%)$ & $50(47 \%)$ \\
Male & $187(48 \%)$ & $561(48 \%)$ & $57(53 \%)$ \\
Mean age (SD) & $36.6(11.8)$ & $36.6(11.8)$ & $36.9(11.5)$ \\
Born in Sweden & $285(73 \%)$ & $931(80 \%)$ & $*$ \\
Monthly income & & & $*$ \\
$>1,000 €$ & $191(49 \%)$ & $334(29 \%)$ & $*$ \\
1,000-2,000€ & $156(40 \%)$ & $312(27 \%)$ & $*$ \\
$<2,000 €$ & $43(11 \%)$ & $524(45 \%)$ & $27(26 \%)$ \\
Diagnosis & & & $25(23 \%)$ \\
Mood disorder (F30-F39) & $124(32 \%)$ & $* *$ & $5(5 \%)$ \\
Psychosis (F20-F29) & $76(20 \%)$ & $* *$ & $7(6 \%)$ \\
Personality disorder (F60-F61) & $55(14 \%)$ & $* *$ & $43(40 \%)$ \\
Dependence disorder (F10-F19) & $22(6 \%)$ & $* *$ & $65(61 \%)$ \\
Other (all other) & $111(28 \%)$ & $* *$ & $30(28 \%)$ \\
Admission & $272(67 \%)$ & $* *$ & $14.3(23.5)$ \\
Involuntary treatment & $105(27 \%)$ & $* *$ & $* 6(90 \%)$ \\
Mean duration of hospitalisation (days) (SD) & $17.2(23.3)$ & $* *$ & $* *$ \\
Hospital & $351(90 \%)$ & $* *$ & $*$ \\
Hospital I & $39(10 \%)$ & & \\
Hospital II & & & \\
\hline & & & \\
\end{tabular}




\section{Controls}

The controls were selected from the annual surveys of living conditions (ULF), conducted by Statistics Sweden [21], which interviews, in person, a representative sample of 6,000 people from the general population. The attrition rate between 2003 and 2006 was $24 \%$. The inclusion criteria of the subjects of the survey are the same as those of the cases except that the survey includes people without a Swedish social security number. The survey covers many aspects of the participants' living conditions, including two specific questions pertaining to experiences of having been victimised.

The controls were selected in a two-step procedure. First, all residents of Stockholm County, interviewed by the ULF survey in the period 2003 through 2006, were identified. Secondly, three controls per case, matched in terms of gender and age, were randomly drawn from this group, resulting in 1,170 controls.

\section{Procedure}

Patients were interviewed from 10 January to 12 December 2007 by two external and independent research assistants. When staff announced that a patient was returning home, he/she was asked to participate (after controlling eligibility). No compensation was offered. A structured 1015 min interview was conducted after discharge by the responsible clinician but before the patient left the hospital building. The participants were assured that the information from the research interview would not be reported to the responsible clinician unless it concerned a threat towards a named person or a case of child mistreatment. The study was approved by Stockholm Regional Ethical Committee (Dnr 2006/1231-31).

\section{Variables}

Data on gender, age, voluntary/involuntary care, admission/not admission and duration of admission of the cases were collected from medical case records. The interview provided further information on socio-economic status, level of education and country of birth using questions from the ULF survey. Diagnosis according to ICD [26] was obtained from the medical case records or via verbal communication with the responsible clinician.

The outcome variable, victimisation, was measured by asking the patients the same two questions as posed to the controls in the ULF survey: "have you been subjected to violence resulting in visible injuries during the last twelve months?" and "have you been subjected to violence that required medical attention during the last twelve months?" The latter type of victimisation is considered more severe than the former. Sexual violence is included, provided it left visible physical marks and/or required medical attention.

Data analysis

All data are presented in terms of descriptive statistics, i.e. mean and standard deviation for continuous data, and frequency and relative frequency for categorical data together with the exact (binominal distribution) 95\% confidence intervals (CI). Participants and refusals were compared using $t$ test for continuous data and Chi-square for categorical data. Data were checked for skewness. All tests were two-tailed and $P<0.05$ was regarded as statistically significant. The crude odds ratios (OR) and the corresponding $95 \% \mathrm{CI}$ of being violently victimised among the cases versus controls were computed using Stata version 10.1 .

\section{Results}

\section{General characteristics}

The 390 patients comprised 203 (52\%) females and 187 $(48 \%)$ males, with a mean age of 36 and 38 years, respectively (Table 1). About half of the patients were diagnosed as having a major mental disorder (schizophrenia, delusional disorder, mood disorder with psychotic symptoms, and unspecified psychosis). Sixty-five percent $(n=252)$ had been admitted; mean duration 17 days. Most cases $(73 \%)$ were in voluntary treatment. Twentyseven percent were not born in Sweden, compared to $20 \%$ of the controls. Forty percent of the patients lacked a 'cash safety margin' of $1,500 €$, i.e. the amount of money that could be raised in an acute situation. The cases had a lower mean economic income than the controls (Table 1). Twenty percent of the cases had not finished 9 years of school, which is the compulsory length of education in Sweden.

\section{Victimisation}

Twenty percent of the patients reported that they had been victimised in the year preceding the interview and half of them, $10.2 \%$ of the whole sample, to the degree that medical attention was needed (Table 2). The corresponding figures for the controls were 3.8 and $1.3 \%$. Victimisation was slightly more prevalent, but not statistically significant, among female rather than male patients, while the reverse was true among the controls (Table 2).

The odds of being victimised was 4.7 (CI 2.6-8.3) for male patients and 10.5 (CI 5.7-19.9) for female patients 
Table 2 Twelve-month rate of violent victimisation in Stockholm among 390 psychiatric patients and 1,170 gender- and age-matched controls in Stockholm Percent $(95 \%$ CI)

\begin{tabular}{|c|c|c|c|c|c|c|}
\hline & \multicolumn{3}{|l|}{ Cases } & \multicolumn{3}{|l|}{ Controls } \\
\hline & Males $(n=187)$ & Females $(n=203)$ & Total $(n=390)$ & Males $(n=561)$ & Females $(n=609)$ & Total $(n=1,170)$ \\
\hline Visible injury & $13.5 \%(9.0-19.1)$ & $15.5 \%(10.6-21.0)$ & $14.5 \%(11.3-18.5)$ & $3.5 \%(2.2-5.5)$ & $2.3 \%(1.3-3.8)$ & $2.9 \%(2.0-4.0)$ \\
\hline Medical attention & $8.5 \%(5.0-13.5)$ & $11.8 \%(7.7-17.0)$ & $10.2 \%(7.2-13.4)$ & $2.1 \%(1.1-3.7)$ & $0.7 \%(0.2-1.7)$ & $1.3 \%(0.7-2.1)$ \\
\hline Any victimisation & $19.2 \%(13.9-25.6)$ & $23.1 \%(17.5-29.6)$ & $20.0 \%(16.1-24.3)$ & $4.9 \%(3.2-6.9)$ & $2.8 \%(1.6-4.4)$ & $3.8 \%(2.8-5.0)$ \\
\hline
\end{tabular}

Table 3 Crude odds ratio for 12-month rate of victimisation among 390 psychiatric patients versus 1,170 gender and age-matched controls in Stockholm

\begin{tabular}{llll}
\hline & Males OR $(95 \% \mathrm{CI}), P$ value & Females OR $(95 \% \mathrm{CI}), P$ value & Total OR $(95 \%$ CI), $P$ value \\
\hline Visible injury & $4.2(2.2-8.1), P<0.001$ & $7.7(3.8-15.9), P<0.001$ & $5.7(3.6-9.2), P<0.001$ \\
Medical attention & $4.3(1.9-11.9), P<0.001$ & $20.3(6.8-81.1), P<0.001$ & $8.8(4.7-17.3), P<0.001$ \\
Any victimisation & $4.7(2.6-8.3), P<0.001$ & $10.5(5.7-19.9), P<0.001$ & $6.4(4.2-9.7), P<0.001$ \\
\hline
\end{tabular}

Cases and controls were tested ( $P$ value) using Chi-square test

(Table 3). The latter were more at risk of victimisation that required medical attention, with an OR of 20.3 (CI 6.881.1). No such difference was noted among male patients.

\section{Discussion}

\section{Victimisation}

The first main finding is that $20 \%$ of general psychiatric patients in Stockholm had been victimised within 1 year prior to interview. A UK study found that $16 \%$ of urban residents with a psychotic disorder had been victimised during the preceding 12 months [25] and 23\% 2 years after inclusion [5]. A study from the UK, France and Germany on people with schizophrenia found that $10 \%$ had been violently victimised during a period of 2.5 years [17]. A Finnish study on patients with schizophrenia, interviewed 3 years after discharge, shows an even lower rate of being victim of a violent crime, $5.6 \%$ [12]. In contrast, a study on severely mentally ill in-patients from inner-city areas of London, reports a considerably higher rate, $53 \%$, of violent victimisation 6 months prior inclusion [10]. These shifting rates may all be attributed to different methodology and definition of victimisation but it is likely that socio-geographic factors, co-morbidity and, possibly, severity of the psychiatric disorder also play a role.

The second main finding, that psychiatric patients were six times more at risk of victimisation than the general population, is compatible with the results of four other controlled studies from New Zealand and the USA [4, 19, 20, 23]. Three of these studies report a 2-4 times higher risk [4, 19, 20], while one shows an 11-fold increase of risk, and as in our study, the relative risk increases with the severity of the violence [23]. However, in order to assess international comparisons of relative rates of victimisation, it is necessary to consider the variation of the base rate of victimisation within the general population of each country. According to an international multi-centre study, the 12 -month rate of violent victimisation in the general population is $3.6 \%$ in Sweden, $4.6 \%$ in Finland, $4.8 \%$ in the UK, $6.0 \%$ in New Zealand and $7.7 \%$ in the USA [24]. Thus, should the rates of victimisation among psychiatric patients follow this pattern, all countries will report similar relative rates, suggesting that the mentally disordered are equally disadvantaged in all the countries concerned. The literature, including this study, lends some support to this view.

There is less international consensus concerning the third main finding that female patients are especially at risk of victimisation, and that this risk is most prominent for more severe types of violence. Some studies report that male patients are more often violently victimised [12, 19, $25]$, others claim that there are no gender differences [5, 7, $8,17]$, while some find female patients to be more often victimised $[1,2]$. The only other study that compares odds ratio with a gender perspective is a retrospective study from USA on 936 individuals with severe mental illness [22]. The results show that the relative risk for completed violent victimisation was 9 for the males and 19 for the females, compared to matched controls.

\section{Limitations}

Recall bias is a potential problem in a study of this kind, although self-report is considered a better measurement of victimisation among psychiatric patients compared to e.g. police-records or other records [13]. Yet, the relative rate 
may be inflated since it is likely that an ongoing therapeutic contact with a psychiatric hospital facilitates the full acknowledgement of having been victimised, while, in contrast, the interviews of the controls were unrelated to a therapeutic setting.

There are at least four possible selection biases of this study. Firstly, the patient group was more disadvantaged than the controls in terms of income and had a somewhat higher rate of individuals born outside Sweden. Secondly, the ULF survey targets residents with an address or a telephone number, which reduces the proportion of homeless, incarcerated, or otherwise socially isolated control subjects. Both of these biases will tend to inflate the odds ratio, since socially marginalised groups are more vulnerable to victimisation [6]. However, a third bias, working in the opposite direction, is that the ULF survey, in contrast to the patient group, includes people without a Swedish social security number, which means that immigrants without residence permits, poor, and socially marginalised people may be overrepresented compared to the patient group. A fourth bias, in our mind the most important one, relates to the fact that patients might be in a hospital because of current victimisation. Having been physically attacked is likely to destabilise the psychiatric condition and promote the need to seek professional advice, although the patients may not always communicate that they have been victimised to the clinicians. Furthermore, the police may transport an assaulted person to hospital for a physical and/or psychiatric checkup. Thus, life-time rate of victimisation would be a better variable for measurement of relative risk of victimisation, since this would be independent of current psychiatric interventions. However, from a clinical point of view, it is of less importance to know the exact relationship between rate of victimisation among patients and non-patients, respectively. What matters is that there are many patients who ought to be identified in terms of their vulnerability to violence by others.

The ambiguous results concerning gender may be related to observational bias. The incitement for women to report victimisation, especially sexual violence, is related to contemporary attitudes in society. If violence towards women is "normalised", there will be little understanding and support for battered women, who, consequently, will be less inclined to report victimisation. On the other hand, in societies with a low acceptance of such violence, such as in Sweden, the reported rate will be higher. However, differences in the relative rate of violent victimisation are not affected by this observational bias, as such societal factors are likely to influence cases and controls equally.

In summary, the strengths of this study are that the number of cases and controls are large enough to produce rather small $\mathrm{CI}$ and the comparatively low proportion of refusals, who, additionally, shared the basic properties of the participants.
The major limitation is that the cases were recruited in a life situation which may be associated with the outcome, in contrast to the controls. However, all in all, we believe that this study presents a fair estimate of the problem of victimisation in a group of general psychiatric patients.

Proper professional management of these patients is likely to increase treatment efficiency and maybe prevent further victimisation [5, 9]. Since so many patients are victimised there is a need for clinical guidelines to screen, support and intervene. There are presently no accepted guideline for the management of adult physical abuse and victimisation, but some work based on patients that have been victimised in childhood, may be applicable for adult victimisation as well [16]. Future studies should provide clinicians with empirical data on specific risk groups, enabling resources to be allocated to where they pay off best. Controlled intervention studies would provide information on the size of the problem and its clinical importance including risk factors such as substance abuse and residential factors.

Acknowledgments The study was funded by grants from The National Board of Health and Welfare, Sweden, and Centre for Gender Medicine at Karolinska Institutet, Sweden. We want to thank Anne Berman, Kristina Sygel and John Monahan for reviewing earlier drafts of this article.

\section{Conflict of interest statement None.}

Open Access This article is distributed under the terms of the Creative Commons Attribution Noncommercial License which permits any noncommercial use, distribution, and reproduction in any medium, provided the original author(s) and source are credited.

\section{References}

1. Brunette MF, Drake RE (1997) Gender differences in patients with schizophrenia and substance abuse. Compr Psychiatry 38(2):109-116

2. Chapple B, Chant D, Nolan P, Cardy S, Whitford H, McGrath J (2004) Correlates of victimization amongst people with psychosis. Soc Psychiatry Psychiatr Epidemiol 39:836-840

3. Choe JY, Teplin LA, Abram KM (2008) Perpetration of violence, violent victimization, and severe mental illness: balancing public health concerns. Psychiatr Serv 59(2):153-164

4. Coverdale JH, Turbott S (2000) Sexual and physical abuse of chronically ill psychiatric outpatients compared with a matched sample of medical outpatients. J Nerv Ment Dis 188:440-445

5. Dean K, Moran P, Fahy T, Tyrer P, Leese M, Creed F, Burns T, Murray R, Walsh E (2007) Predictors of violent victimization amongst those with psychosis. Acta Psychiatr Scand 116:345-353

6. Estrada F, Nilsson A (2003) Victimization, inequality and welfare during an economic recession: a study of self-reported victimization in Sweden 1988-99. Br J Criminol 43:655-672

7. Goodman LA, Salyers MP, Meuser KT et al (2001) Recent victimization in woman and men with severe mental illness: prevalence and correlates. J Traum Stress 14(4):615-632 
8. Hiday VA, Swartz MS, Swanson JW, Borum R, Wagner HR (1999) Criminal victimization of persons with severe mental illness. Psychiatr Serv 50(1):62-68

9. Hiday VA, Swartz MS, Swanson JW, Borum R, Wagner HR (2002) Impact of outpatient commitment on victimization of people with severe mental illness. Am J Psychiatry 159:14031411

10. Hodgins S, Alderton J, Cree A, Aboud A, Mak T (2007) Aggressive behaviour, victimisation and crime among severely mentally ill patients requiring hospitalisation. Br J Psychiatry 191:343-350

11. Hodgins S, Lincoln T, Mak T (2009) Experiences of victimisation and depression is associated with community functioning among men with schizophrenia. Soc Psychiatry Psychiatr Epidemiol 44:448-457

12. Honkonen T, Henriksson M, Koivisto AM, Stengård E, Salokangas RK (2004) Violent victimization in schizophrenia. Soc Psychiatry Psychiatric Epidemiol 39:606-612

13. Kooyman I, Dean K, Harvey S, Walsh E (2007) Outcomes of public concerns in schizophrenia. Br J Psychiatry 191:s29-s36

14. Lam JA, Rosenheck R (1998) The effect of victimization on clinical outcomes of homeless persons with serious mental illness. Psychiatr Serv 49:678-683

15. Read J, Agar K, Argyle N, Aderhold V (2003) Sexual and physical abuse during childhood and adulthood as predictors of hallucinations, delusions and thought disorder. Psychol Psychother Theory Res Pract 76:1-22

16. Read J, Hammarsley P, Rudegeair T (2007) Why, when and how to ask about childhood abuse. Adv Psychiatr Treat 13:101-110

17. Schomerus G, Heider D, Angermeyer MC, Bebbington PE, Azorin J-M, Brugha T, Toumi M (2007) Urban residence, victimhood and the appraisal of personal safety in people with schizophrenia: results from the European Schizophrenia Cohort (EuroSC). Psychol Med 38:591-597

18. Sells DJ, Rowe M, Fisk D, Davidson L (2003) Violent victimization of persons with co-occuring psychiatric and substance use disorders. Psychiatr Serv 54(9):1253-1257

19. Silver E (2002) Mental disorder and violent victimization: the mediating role of involvement in conflicted social relationship. Criminology 40:191-212

20. Silver E, Arsenault L, Langley J, Caspi A, Moffit TE (2005) Mental disorder and violent victimization in a total birth cohort. Am J Public Health 95(11):2015-2021

21. Statistics Sweden (2009) http://www.scb.se/Pages/Product 12187.aspx

22. Taylor RE, Leese M, Clarkson P, Holloway F, Thornicroft G (1998) Quality of life outcomes for intensive versus standard community mental health services. Br J Psychiatry 173:416-422

23. Teplin LA, McClelland GM, Abram KM, Weiner DA (2005) Crime victimization in adults with severe mental illness: comparison with the national crime victimization survey. Arch Gen Psychiatry 62:911-921

24. van Wilsem $\mathbf{J}$ (2004) Criminal victimization in cross-national perspective. An analysis of theft, violence and vandalism across 27 countries. Eur J Criminol 1:89-109

25. Walsh E, Moran P, Scott C, McKenzie K, Burns T, Creed F, Tyrer P, Murray RM, Fahy T (2003) Prevalence of violent victimisation in severe mental illness. Br J Psychiatry 183:233-238

26. World Health Organization (1992) The tenth revision of the international classification of diseases and related health problems (ICD-10). WHO, Geneva 